\title{
Desain Panduan Audit Tata Kelola Sistem Informasi Boost The Order (SIBORDER) di PT Telekomunikasi Indonesia Menggunakan COBIT 2019
}

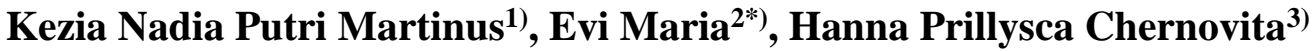 \\ 1,2,3 Departemen Sistem Informasi, Fakultas Teknologi Informasi, Universitas Kristen Satya Wacana \\ ${ }^{*}$ Correspondence Author: evi.maria@uksw.edu, Salatiga, Indonesia
}

DOI: $\underline{\text { https://doi.org/10.37012/jtik.v7i2.638 }}$

\begin{abstract}
Abstrak
PT Telekomunikasi Indonesia Tbk (Telkom) bergerak di bidang layanan teknologi informasi dan komunikasi serta jaringan. Teknologi informasi (TI) berperan penting dalam proses bisnis PT Telkom, sehingga perlu dikelola menggunakan kerangka kerja Control Objectives for Business and Related Technology (COBIT). COBIT 2019 mengakomodasi tren TI baru dalam bisnis, sehingga dapat berfungsi sebagai panduan bagi auditor, pengguna dan pihak manajemen untuk menjembatani kesenjangan antara risiko, pengendalian, dan masalah teknis di PT Telkom khususnya dalam pengelolaan Sistem Informasi Boost The Order (SIBORDER). Audit tata kelola TI adalah mekanisme kontrol pengelolaan SIBORDER. Oleh sebab itu, sebelum pelaksanaan audit, auditor perlu membuat perencanaan audit untuk memudahkan ketika mengalokasikan sumber daya sehingga pelaksanaan audit berjalan efektif dan efisien. Riset ini bertujuan untuk mendesain panduan audit tata kelola SIBORDER menggunakan kerangka kerja COBIT 2019. Desain dimulai pertama, dengan identifikasi kebutuhan stakeholder, enterprise goals dan pembobotan faktor desain. Hasil kebutuhan stakeholder, yaitu optimalisasi risiko dan sumber daya, sedangkan enterprise goals, yaitu EG01, EG05, EG06 dan EG13, dan hasil identifikasi domain sebagai fokus area, yaitu BAI 10, DSS 03, DSS 04 dan DSS 05. Kedua, penetapan sumber informasi berdasarkan RACI Chart. Ketiga, pembuatan lembar kerja audit yang berisi daftar pertanyaan untuk penilaian domain terpilih dan jadwal pelaksanaan audit.
\end{abstract}

Kata Kunci: Audit Tata Kelola TI, Teknologi Informasi, COBIT 2019, Panduan Audit, SIBORDER

\begin{abstract}
PT Telekomunikasi Indonesia Tbk (Telkom) is engaged in information and communication technology and network services. Information technology (IT) plays an important role in PT Telkom's business processes, so it needs to be managed using the Control Objectives for Business and Related Technology (COBIT) framework. COBIT 2019 accommodates new IT trends in business, so that it can serve as a guide for auditors, users and management to bridge the gap between risk, control, and technical problems at PT Telkom, especially in the management of the Boost The Order (SIBORDER) Information System. IT governance audit is a control mechanism for SIBORDER management. Therefore, before conducting the audit, the auditor needs to make an audit plan to make it easier when allocating resources so that the audit is carried out effectively and efficiently. This research aims to design a SIBORDER governance audit guide using the COBIT 2019 framework. The design begins first, by identifying stakeholder needs, enterprise goals and weighting design factors. The results of stakeholder needs, namely optimizing risk and resources, while enterprise goals, namely EG01, EG05, EG06 and EG13, and the results of domain identification as focus areas, namely BAI 10, DSS 03, DSS 04 and DSS 05. Second, determination of information sources based on the RACI Chart. Third, the creation of an audit worksheet that contains a list of questions for the assessment of the selected domain and the schedule of audit implementation.
\end{abstract}

Keywords: IT Governance Audit, Information Technology, COBIT 2019, Audit Guide, SIBORDER 


\section{PENDAHULUAN}

Dalam rangka mencapai tujuannya, perusahaan tidak bisa lepas dari penggunaan teknologi informasi (TI). TI menjadi isu utama dalam perencanaan strategis dan peningkatan kinerja di banyak perusahaan. Tak hanya memiliki manfaat, TI juga memiliki risiko. Oleh sebab itu, pihak manajemen perlu memahami risiko dan peluangnya ketika membuat keputusan TI dan investasinya. TI perlu dikelola dengan baik, agar fungsi dan proses bisnis dalam perusahaan dapat berjalan efektif, efisien, dan ekonomis.

Tata kelola TI (IT governance) merupakan bagian integral dari tata kelola organisasi (corporate governance) yang menjadi tanggungjawab manajemen puncak dan dewan direksi (Sari et al., 2014). Tata kelola TI fokus pada optimalisasi peran TI dalam memberikan nilai tambah bisnis dan mengurangi terjadinya risiko fraud dalam perusahaan (Servanda \& Mutiara, 2018) . TI selalu terkait dengan aset perusahaan, seperti keuangan, sumber daya manusia, dan lain-lain, sehingga pengelolaan TI perlu memperhatikan banyak faktor.

Prinsipnya, TI harus dikelola agar organisasi dapat efektif, transparan dan akuntabel dalam pencapaian tujuannya tak terkecuali di PT Telekomunikasi Indonesia (Persero) Tbk (Telkom). PT Telkom merupakan salah satu Badan Usaha Milik Negara (BUMN) yang menyediakan jasa layanan teknologi informasi dan komunikasi serta jaringan telekomunikasi di Indonesia (PT Telekomunikasi Indonesia Tbk, 2021). TI mendukung seluruh proses bisnis internal dan eksternal PT Telkom. Layanan informasi dan komunikasi prima menjadi tuntutan seluruh pengguna layanan PT Telkom. Peraturan Menteri Badan Usaha Milik Negara Republik Indonesia No. PER-03/MBU/02/2018 tentang Prinsip Tata Kelola Teknologi Informasi Kementerian Badan Usaha Milik Negara, mengamanatkan bahwa seluruh BUMN di Indonesia wajib untuk memiliki tata kelola TI dalam rangka mengatur sumber daya TI secara efektif dan efisien. Kondisi ini membuat tata kelola TI menjadi isu yang menarik untuk dibahas di PT Telkom.

Tata kelola TI memerlukan kerangka kerja sebagai acuan untuk memastikan bahwa TI dikelola secara berkualitas, sehingga tujuan, peran, tanggungjawab, implementasi, terminologi, kerangka konseptual dan tingkat kematangan dapat diidentifikasi (Waluyab \& Manuputty, 2016). Control Objectives for Business and Related Technology (COBIT) dapat digunakan sebagai kerangka kerja tata kelola TI sekaligus sebagai kerangka kerja audit sistem TI (Mihai, 2010)(Riyandi et al., 2020). Kerangka ini berisi praktik terbaik tata kelola TI, sehingga dapat menjadi panduan tak hanya bagi auditor, tetapi juga bagi pengguna dan pihak manajemen untuk menjembatani kesenjangan antara risiko, pengendalian dan masalah 
teknis TI (Mihai, 2010)(Hamsir et al., 2017). Kerangka kerja COBIT bermanfaat dalam aktivitas perencanaan strategis TI, pengambilan keputusan investasi dan arsitektur TI, serta membantu proses identifikasi dan evaluasi pengendalian TI dalam rangka menjamin kehandalan sistem informasi yang digunakan oleh perusahaan (Tambotoh \& Latuperissa, 2014).

Riset terdahulu terkait tata kelola TI di PT Telkom telah dilakukan, seperti riset (Waluyab \& Manuputty, 2016)(Hamsir et al., 2017)(Fariani, 2014)(Ramdhany \& Nur'adila, 2020). Evaluasi tata kelola TI di PT Telkom dilakukan menggunakan kerangka kerja COBIT, yaitu COBIT 4.1 dan COBIT 5. Evaluasi tata kelola TI, riset sebelumnya telah dilakukan pada sistem informasi starclick, yaitu aplikasi untuk input data pelanggan di PT Telkom Semarang (Waluyab \& Manuputty, 2016), sistem informasi keuangan di PT Telkom Makassar (Hamsir et al., 2017), IT governance (Fariani, 2014), sistem informasi pengawasan dan permintaan layanan dan insiden di PT Telkom (Ramdhany \& Nur'adila, 2020) dan proses monitoring, evaluasi dan pengendalian internal di PT Telkom Semarang (Meilinda, 2016). Evaluasi dilakukan dengan tujuan untuk memberikan penilaian tingkat kematangan TI dan rekomendasi perbaikan pengelolaan TI di PT Telkom. Riset terdahulu di PT Telkom belum menggunakan kerangka kerja terbaru COBIT hasil penyempurnaan COBIT 5, yaitu COBIT 2019 sebagai kerangka kerja tata kelola TI dan audit tata kelola TI. Kerangka kerja COBIT 2019 telah mengakomodasi tren TI baru dalam bisnis, seperti transformasi digital TI. Riset terdahulu terkait perancangan tata kelola TI menggunakan COBIT 2019 sudah dilakukan, seperti yang dilakukan oleh Bayastura et al. di kedai kopi (Bayastura et al., 2021), Fikri et al. di perusahaan agrifood (Fikri et al., 2020), Anastasia dan Atrinawati di hotel (Anastasia \& Atrinawati, 2020), Adawiyah dan Atrinawati di perusahaan bidang jasa fabrikasi dan inspeksi (Adawiyah \& Atrinawati, 2020). Namun, belum ada riset yang menggunakan COBIT 2019 sebagai kerangka kerja untuk melakukan audit tata kelola TI, sehingga riset audit tata kelola TI menggunakan kerangka kerja COBIT 2019 menarik untuk dilakukan.

PT Telkom memiliki sistem informasi boost the order (SIBORDER), yaitu sistem informasi yang berfungsi untuk mengawasi proses pemasangan dan upgrade kabel base transceiver station (BTS). Ada empat order yang diawasi oleh SIBORDER, yaitu order fiber rollout (pemasangan BTS menggunakan fiber optic), fiber modernization (proses modernisasi fiber optic), radio rollout (pemasangan BTS menggunakan gelombang radio), radio modernization (proses modernisasi gelombang radio). SIBORDER belum pernah dilakukan audit tata kelola TI, sehingga efektifitas dan efisiensi pengelolaan SIBORDER belum diketahui. Sebelum melakukan audit, auditor internal akan membuat desain panduan audit 
tata kelola (Eko et al., 2013). Tujuannya untuk membantu memudahkan auditor mengalokasikan sumber daya dalam penugasan auditnya. Oleh sebab itu, riset ini dilakukan dengan tujuan untuk mendesain panduan audit tata kelola untuk implementasi SIBORDER dengan menggunakan kerangka kerja COBIT 2019. Kerangka kerja ini dipilih karena COBIT 2019 mengatur prinsip kerangka kerja dan sistem tata kelola TI yang fleksibel dan terbuka untuk diterapkan di perusahaan (Lanter, 2019) (Lanter, 2019)(Putra et al., 2020) dan struktur model kinerja manajemen TI terintergasi dengan model konseptual TI (Lanter, 2019).

Panduan audit diharapkan memberikan dua kontribusi. Pertama, bagi pengembangan ilmu di bidang sistem informasi, panduan audit tata kelola TI membantu menjembatani teori dan praktik pengelolaan TI dengan mengimplementasikan kerangka kerja tata kelola TI versi terbaru, yaitu COBIT 2019 di perusahaan telekomunikasi terbesar di Indonesia. Kedua, panduan audit membantu auditor internal di PT Telkom dalam melakukan tugas perencanaan audit, yaitu kegiatan yang dilakukan sebelum penugasan lapangan audit dilakukan.

\section{METODE PENELITIAN}

Riset ini menggunakan metode kualitatif dengan melakukan pengamatan yang mendalam pada fenomena dan obyek yang diteliti, yaitu SIBORDER di PT Telkom. Metode ini dipilih karena riset ini bertujuan untuk merancang panduan audit tata kelola untuk implementasi SIBORDER menggunakan COBIT 2019 sebagai kerangka kerjanya. Data primer riset ini diperoleh melalui wawancara dan observasi terhadap penerapan dan pengelolaan SIBORDER di PT Telkom. Sedangkan data sekunder riset ini diperoleh melalui studi dokumentasi terhadap dokumen-dokumen perusahaan terkait pengelolaan SIBORDER di PT Telkom dan studi literatur dari riset-riset terdahulu terkait tata kelola sistem informasi menggunakan framework COBIT.

Dalam membuat desain panduan audit tata kelola TI untuk implementasi SIBORDER di PT Telkom, ada empat tahap kegiatan yang dilakukan. Tahapan desain panduan audit tata kelola TI disajikan pada Gambar 1. 


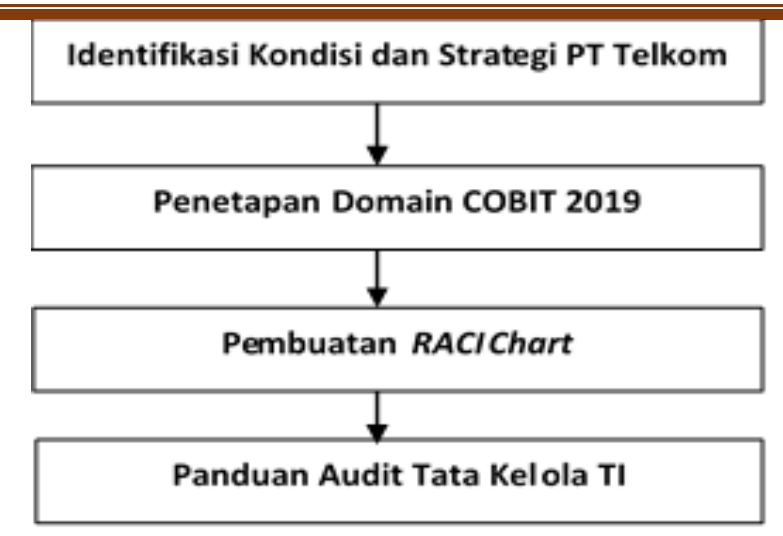

Gambar 1. Tahap Desain Panduan Audit Tata Kelola SIBORDER.

Tahap pertama, identifikasi kondisi dan strategi perusahaan, yaitu PT Telkom. Informasi tentang strategi, tujuan, profil risiko dan TI yang dimiliki dan dikelola oleh perusahaan diperoleh dari website PT Telkom di https://www.telkom.co.id/sites/about-telkom/, wawancara dengan supervisor divisi TI dan praktik kerja. Informasi terkait SIBORDER dan standar operasional prosedur (SOP) diperoleh dari hasil wawancara. Dalam tahap ini, dilakukan reviu terhadap panduan kerangka kerja COBIT 2019, meliputi prinsip dan sistem tata kelola TI serta riset terdahulu tentang tata kelola TI dengan kerangka kerja COBIT agar diperoleh pemahaman terkait implementasi kerangka kerja COBIT dalam rangka membuat desain panduan audit tata kelola TI.

Tahap kedua, penetapan domain berdasarkan COBIT 2019 goals cascade, seperti yang terlihat pada Gambar 2. Pada tahap ini ada tiga aktivitas. Pertama, terjemahkan pemicu dan kebutuhan stakeholder. Kedua, identifikasi tujuan bisnis (enterprise goals) ke dalam tujuan penyelarasan (alignment goals) prioritas. Tujuan penyelarasan, fokus pada keselarasan semua usaha TI dengan tujuan bisnis PT Telkom. COBIT 2019 cascade goals berbeda dengan versi sebelumnya karena tujuan bisnis dan tujuan penyelarasan telah dikonsolidasikan, dikurangi, diperbaharui dan diklarifikasi (Tambotoh \& Latuperissa, 2014). Ketiga, identifikasi faktor desain tata kelola dan tujuan manajamen dengan cara melakukan pembobotan faktor desain berdasarkan kondisi aktual yang ada di PT Telkom dengan kerangka kerja COBIT 2019. Pembobotan faktor desain menggunakan alat bantu, yaitu audit toolkit COBIT 2019 (Belo et al., 2020). Setelah itu, dilakukan pemetaan dengan tabel mapping COBIT 2019, hasilnya akan didapatkan domain mana saja yang menjadi prioritas dan bukan prioritas. Adapun kombinasi faktor desain COBIT 2019 disajikan pada Gambar 3. 


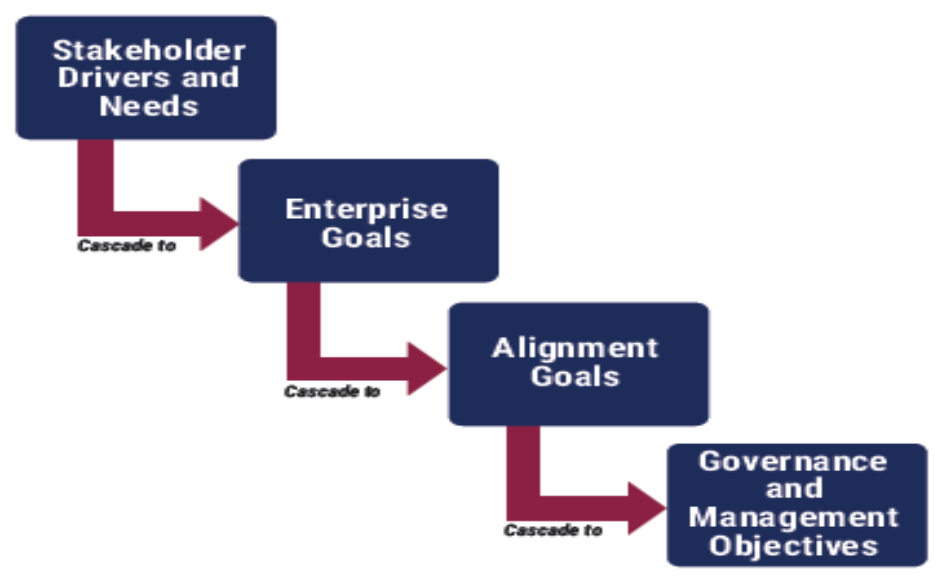

Gambar 2. COBIT 2019 Goals Cascade (Tambotoh \& Latuperissa, 2014)
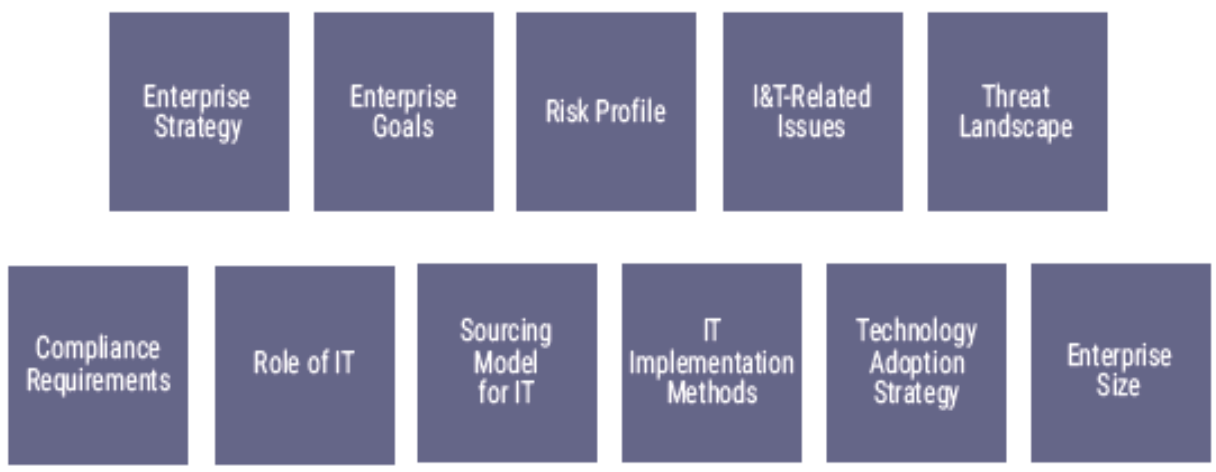

\section{Future Factors}

Gambar 3. Faktor Desain COBIT 2019 (Tambotoh \& Latuperissa, 2014)

Tahap ketiga, pemetaan RACI-chart (Responsible-Accountable-Consulted-Informed) ke dalam struktur organisasi PT Telkom. RACI-chart adalah matriks untuk menentukan sasaran pihak-pihak yang akan menjadi informan kunci untuk memperoleh informasi pengelolaan TI, khususnya SIBORDER di PT Telkom. Panduan COBIT 2019 (Lanter, 2019) mendefinisikan responsible, yaitu pihak yang memiliki tanggungjawab pada pelaksanaan aktivitas. Accountable, yaitu pihak yang bertugas memberi arahan dalam pelaksanaan aktivitas. Consulted, yaitu pihak yang dilibatkan ketika mengambil keputusan pelaksanaan aktivitas. Sedangkan informed, yaitu pihak yang diberi laporan pelaksanaan aktivitas. Auditor akan melaksanakan audit tata kelola TI akan menggunakan kuesioner. Kuesioner disusun berdasarkan aktivitas yang ada dalam COBIT 2019. Penilaian menggunakan skema kapabilitas proses berbasis Capability Maturity Model Integration (CMMI), yaitu menilai kematangan dan kemampuan organisasi dalam pengelolaan TI (Lanter, 2019). Informan kunci akan diminta untuk memberikan penilaian mulai dari 0-5 atas kondisi pengelolaan SIBORDER, seperti yang disajikan pada Gambar 4. 


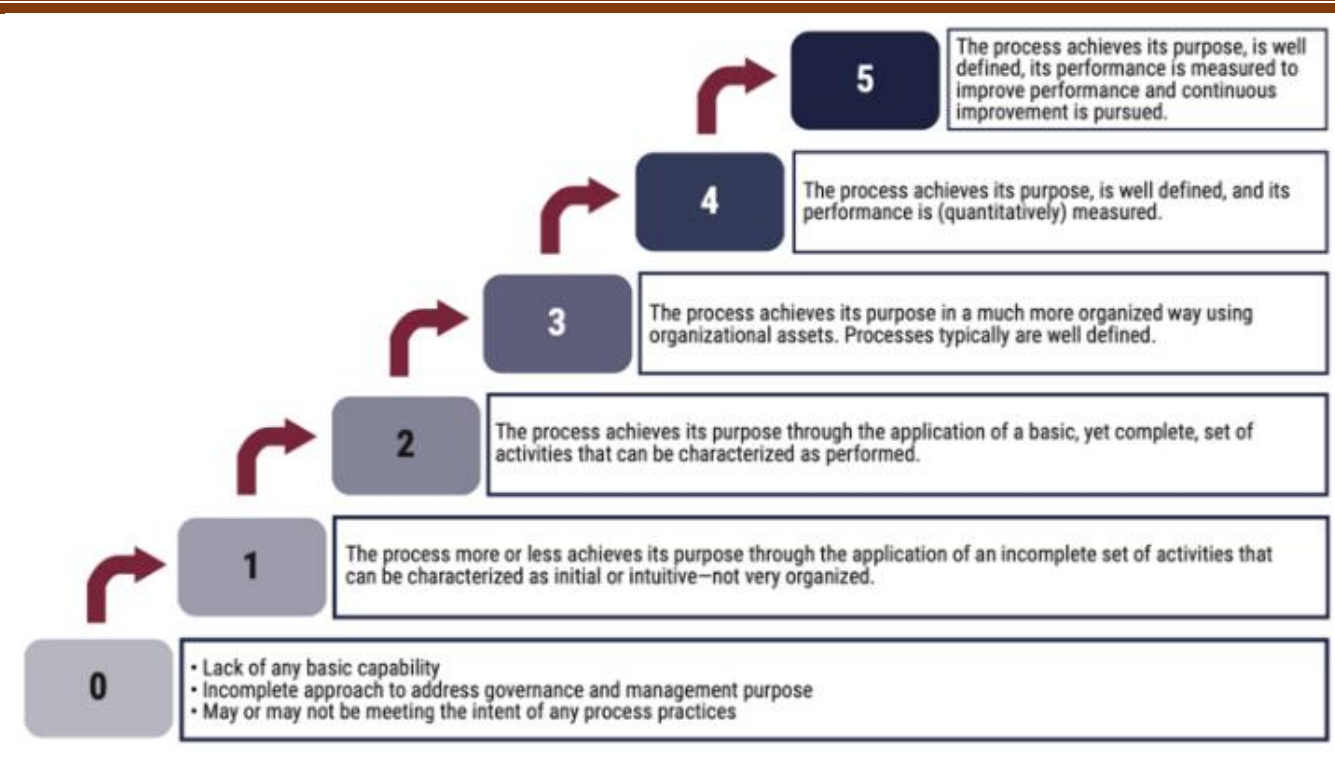

Gambar 4. Tingkat kemampuan berdasarkan CMMI pada COBIT 2019.

Tahap keempat, penyusunan panduan audit tata kelola SIBORDER, meliputi kegiatan membuat kuesioner/lembar kerja audit berdasarkan domain COBIT 2019 yang terpilih di tahap sebelumnya dan membuat jadwal rencana pelaksanaan audit tata kelola SIBORDER. Kuesioner akan diberikan pada informan kunci sesuai dengan penetapan RACI-Chart pada domain prioritas yang telah ditentukan pada tahap sebelumnya. Hasil audit berupa penilaian kondisi pengelolaan SIBORDER dituangkan dalam lembar kerja audit.

\section{HASIL DAN PEMBAHASAN}

Bagian ini berisi hasil identifikasi kebutuhan stakeholder, tujuan bisnis, tujuan penyelarasan dan faktor desain sebagai penentu domain. Identifikasi kebutuhan stakeholder diperoleh melalui wawancara dengan karyawan dan supervisor divisi TI dan observasi terhadap SIBORDER dan pengelolaannya dilakukan dengan pendekatan kerja praktek di PT Telkom selama 4 bulan. Hasil identifikasi kebutuhan stakeholder disajikan pada Tabel I.

Tabel 1. Identifikasi Kebutuhan Stakeholder

Kebutuhan Keterangan

Optimalisasi Dalam menjalankan bisnis dengan penggunaan aset TI, PT Telkom membutuhkan biaya Risiko investasi TI yang tinggi. Kondisi ini mendorong perusahaan perlu untuk melakukan proses manajemen risiko dalam rangka optimasi risiko bisnis. Tujuannya, untuk memperkecil risiko terjadinya kerugian dan munculnya masalah dan/atau hambatan ketika PT Telkom menggunakan aset TI untuk kegiatan bisnis dan operasionalnya. Kondisi ini mendorong aset TI perlu dikelola dan dipelihara dengan baik agar risiko kerusakan aset fisik TI, kehilangan data, keamanan sistem informasi, kegagalan implementasi TI serta penggunaan aset TI yang 
tidak sesuai kebutuhan dapat dicegah dan diminimalisir, sehingga pelayanan jasa telekomunikasi kepada pelanggan tidak terganggu.

Optimalisasi Strategi bisnis dan layanan PT Telkom yang berorientasi pada pelanggan serta terdepan dalam Sumber Daya pelayanan TI di industri digital Indonesia, menuntut PT Telkom untuk selalu beradaptasi dengan perkembangan TI. Oleh sebab itu, PT Telkom terus berupaya untuk melakukan kegiatan optimaliasi penggunaan sumber daya perusahaan sesuai dengan tugas dan fungsinya. Tujuannya, agar PT Telkom dapat beroperasi secara efektif, efisien dan ekonomis.

Dalam rangka menjawab tantangan industri digital di Indonesia, PT Telkom berusaha untuk memberikan layanan terbaik dan memberikan nilai tambah bagi seluruh stakeholders-nya (PT Telekomunikasi Indonesia Tbk, 2021). Hasil identifikasi kebutuhan stakeholder pada tahap sebelumnya, digunakan untuk mengidentifikasi tujuan bisnis (enterprise goals). Hasil identifikasi tujuan bisnis PT Telkom disajikan pada Tabel II.

Tabel 2 Identifikasi Enterprise Goals

\begin{tabular}{ccl}
\hline Perspektif Balance Score Card (BSC) & Kode & Enterprise Goals \\
\hline Keuangan & EG01 & Portofolio produk dan layanan yang kompetitif \\
Pelanggan & EG05 & Budaya layanan berorientasi pelanggan \\
\cline { 2 - 3 } & EG06 & Keberlanjutan dan ketersediaan layanan bisnis \\
\hline Pembelajaran dan Pertumbuhan & EG13 & Inovasi produk dan bisnis \\
\hline
\end{tabular}

Selanjutnya identifikasi faktor desain sebagai langkah terakhir dalam penentuan domain. Tahap ini merupakan karakteristik dari objek audit. Tahap ini menentukan ruang lingkup sistem tata kelola (governance systems) dengan mempertimbangkan faktor desain 1 sampai faktor desain 11 yang dijabarkan sebagai berikut:

\section{1) Faktor Desain 1 Enterprise Strategy}

Tahap ini dilakukan proses identifikasi strategi bisnis PT Telkom. Ada empat jenis strategi perusahaan, yaitu growth/acquisition, innovation/differentiation, cost leadership dan client service/stability. Jenis strategi dengan penilaian tertinggi pada PT Telkom adalah client service/stability. Ini karena PT Telkom berfokus kepada penyediaan layanan yang stabil dan fokus pada pelanggan. 


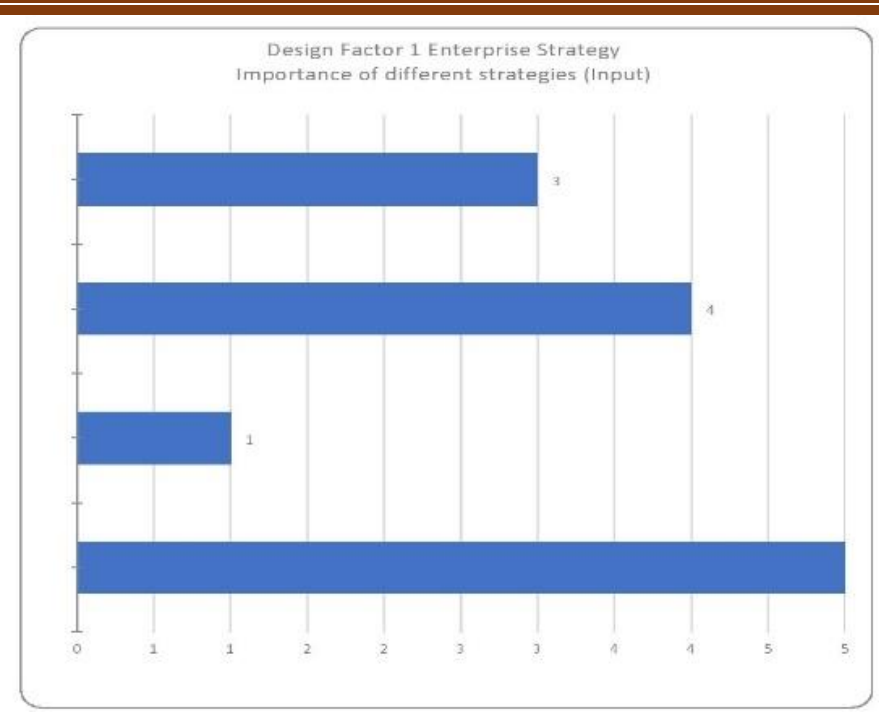

Gambar 5. Faktor desain 1

\section{2) Faktor Desain 2 Enterprise Goals}

Tahap ini dilakukan proses identifikasi tujuan bisnis PT Telkom. Pada COBIT 2019 tujuan bisnis perusahaan dibagi menjadi 13 jenis. Hasil identifikasi PT Telkom memiliki empat tujuan bisnis yang mendapat nilai 5, yaitu EG01 portofolio produk dan layanan yang kompetitif, EG05 budaya layanan yang berorientasi pada pelanggan, EG06 keberlanjutan dan ketersediaan layanan bisnis dan EG13 inovasi produk dan bisnis.

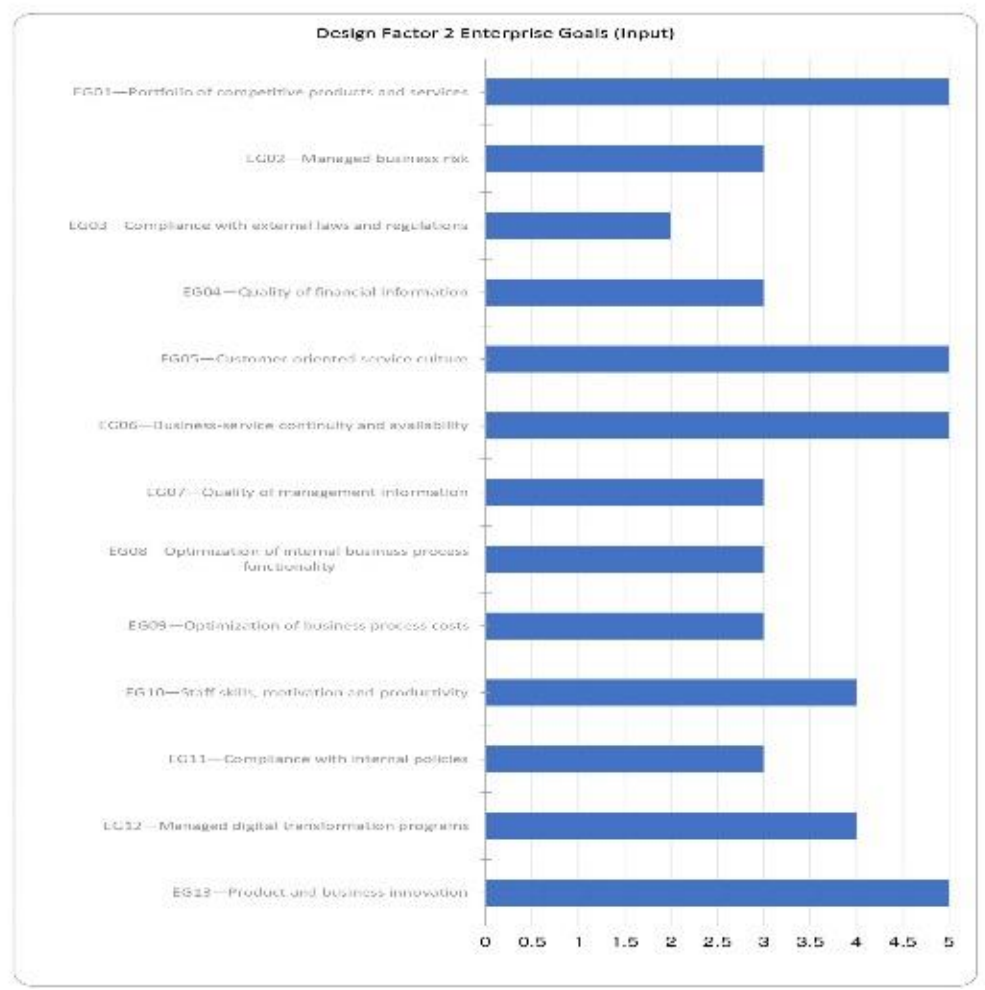

Gambar 6. Faktor desain 2 


\section{3) Faktor Desain 3 Risk Profile}

Tahap ini dilakukan proses indetifikasi profil risiko yang dimiliki PT Telkom. Risiko dengan nilai tertinggi di PT Telkom adalah software adoption/usage problem yang berkaitan dengan permasalahan yang muncul saat perangkat lunak digunakan.

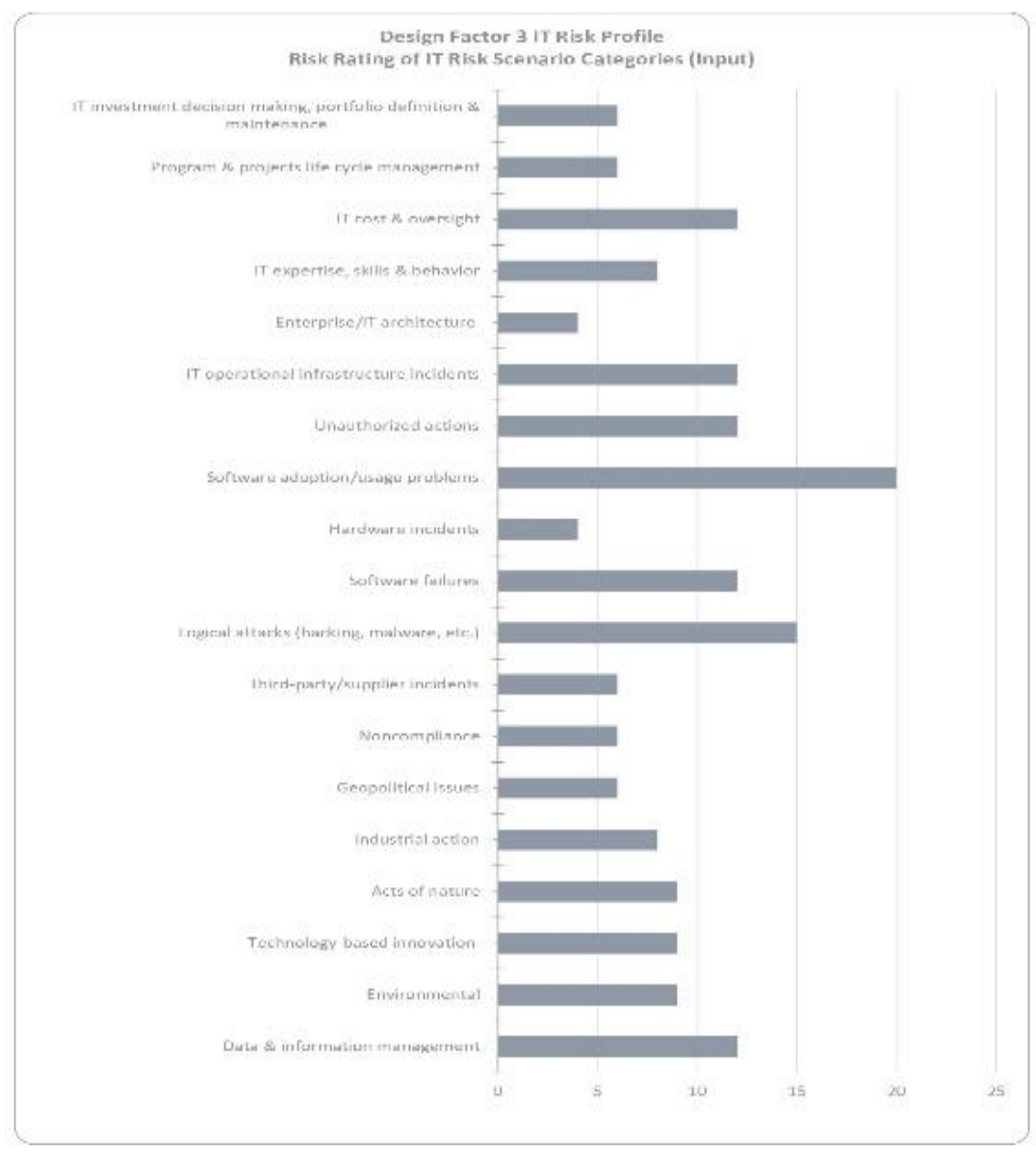

Gambar 7. Faktor desain 3

\section{4) Faktor Desain 4 I\&T Related Issues}

Tahap ini dilakukan proses identifikasi permasalahan terkait TI yang dihadapi PT Telkom dalam pengelolaan SIBORDER. Permasalahan TI yang paling sering ditemukan adalah insiden TI yang signifikan seperti kehilangan data, pelanggaran keamanan, kegagalan proyek dan kesalahan pada aplikasi saat dijalankan. 


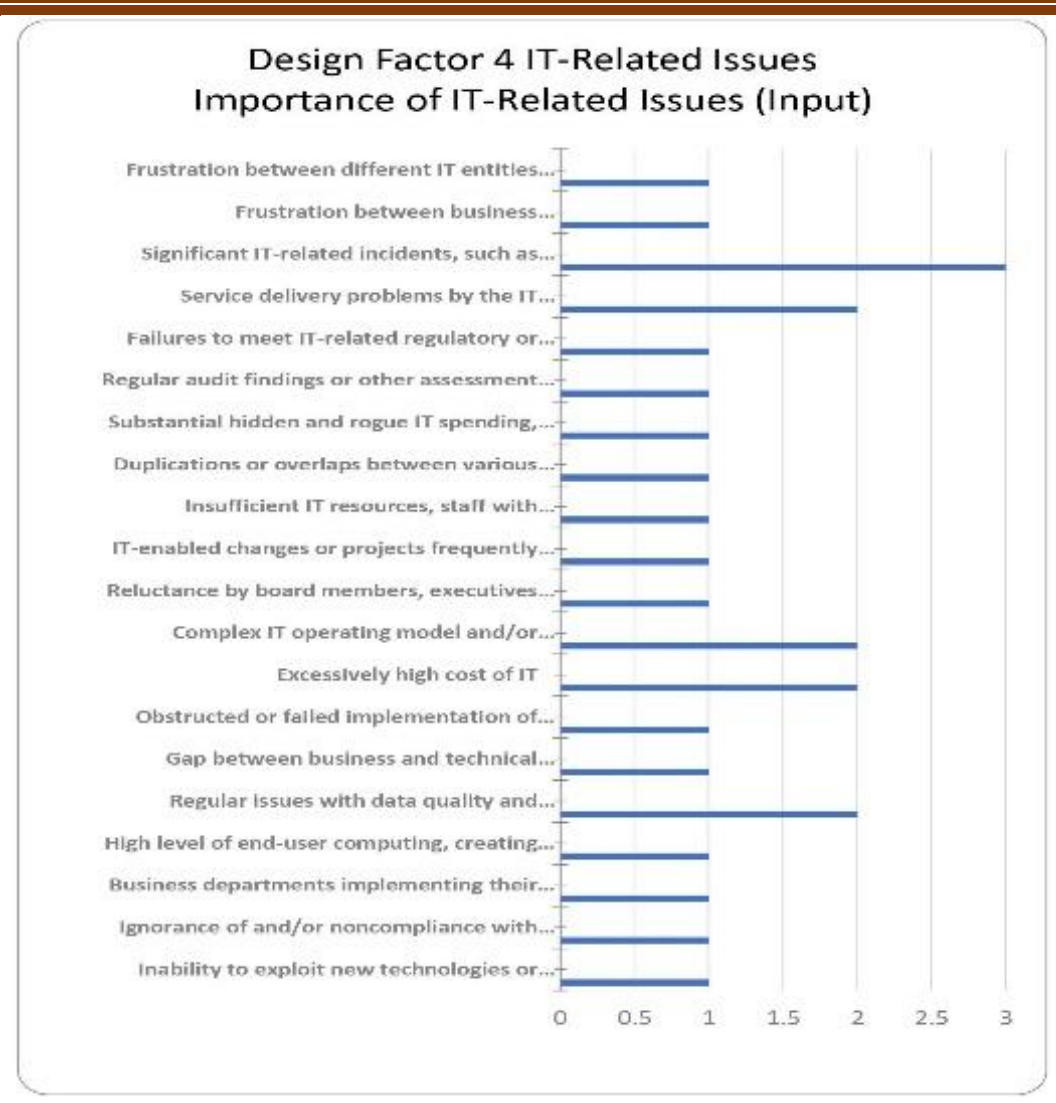

Gambar 8. Faktor Desain 4

\section{5) Faktor Desain 5 Threat Landscape}

Tahap ini dilakukan proses identifikasi tipikal ancaman yang dihadapi PT Telkom dalam pengelolaan SIBORDER. Ada dua level ancaman, yaitu ancaman level tinggi dan normal. Dari sisi level ancaman, PT Telkom presentase lebih cenderung ke arah normal karena sebagian besar ancaman yang dihadapi tidak terlalu mengganggu SIBORDER dalam menjalankan proses bisnis.

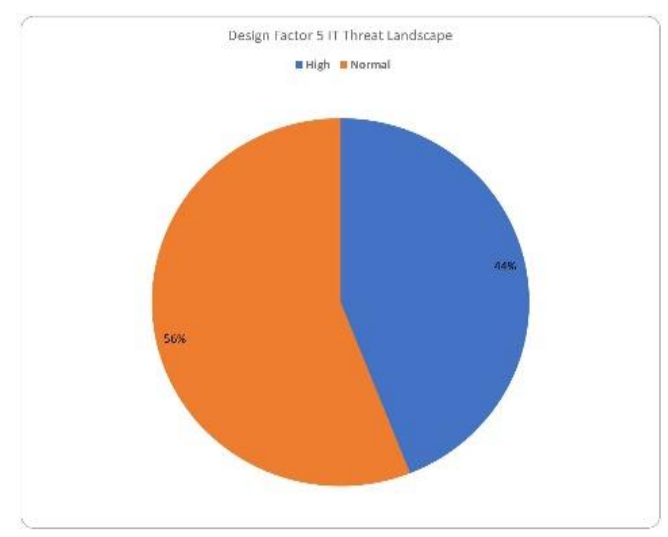

Gambar 9. Faktor Desain 5 


\section{6) Faktor Desain 6 Compliance Requirements}

Tahap ini dilakukan proses identifikasi kepatuhan PT Telkom terhadap peraturan. Ada tiga level kepatuhan, yaitu level tinggi, normal dan rendah. PT Telkom memiliki kepatuhan pada level tinggi. PT Telkom memiliki divisi VP Legal and compliance tersendiri. Adapun tugas dari divisi ini adalah memastikan pemenuhan seluruh peraturan yang ada dan menjadi kewajiban untuk dilakukan.

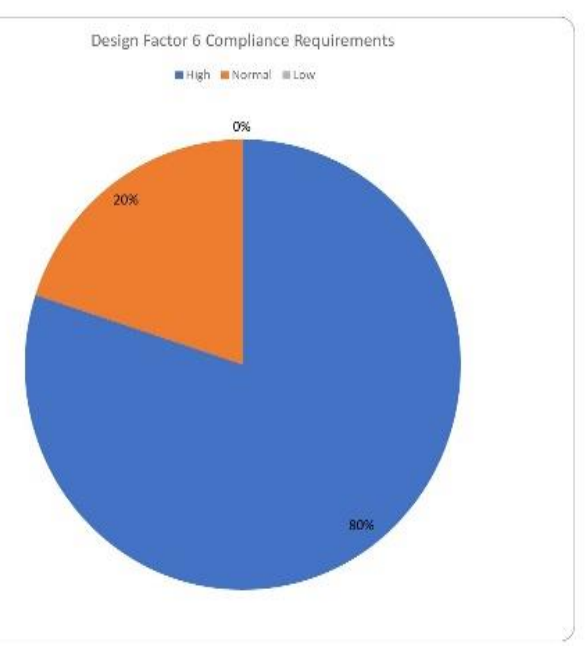

Gambar 10. Faktor Desain 6

\section{7) Faktor Desain 7 Role of IT}

Tahap ini dilakukan proses identifikasi peran TI dalam pengelolaan SIBORDER di PT Telkom. Ada empat jenis peran TI dalam perusahaan, yaitu support, factory, strategic dan turnaround. Jenis peran TI dengan penilaian tertinggi di PT Telkom adalah strategic. Artinya TI memiliki peran sangat penting untuk menjalankan dan melakukan inovasi pada proses bisnis dan layanan dalam hal ini terkait SIBORDER. 


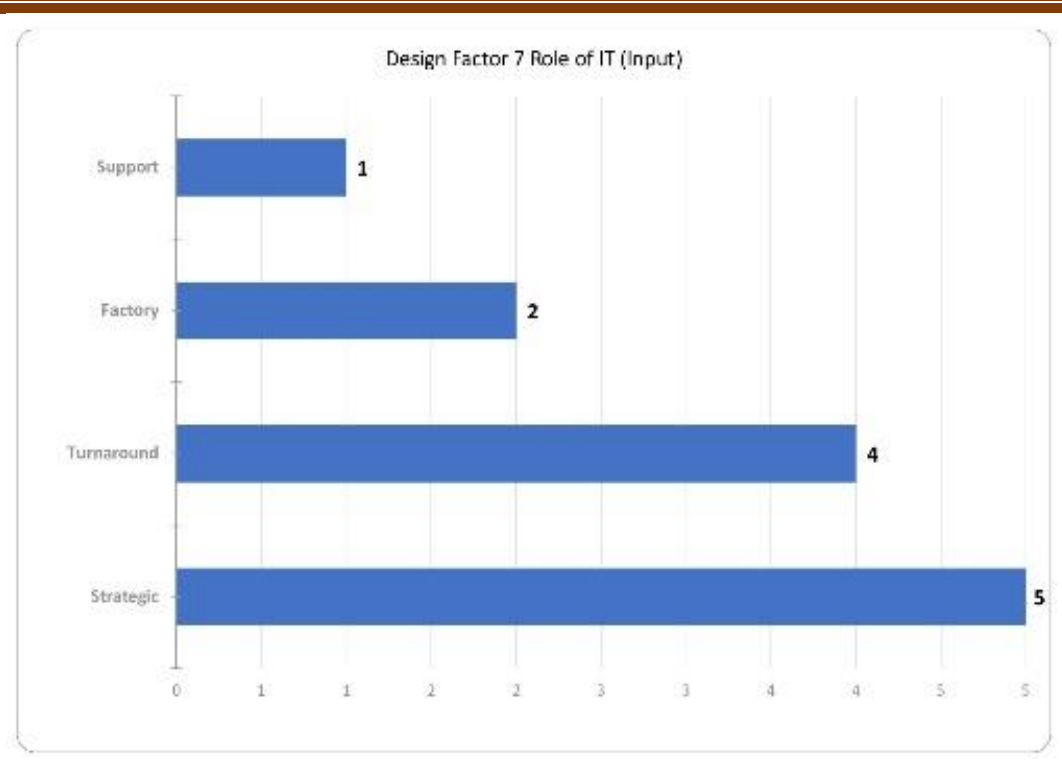

Gambar 11. Faktor Desain 7

\section{8) Faktor Desain 8 Sourcing Model of IT}

Tahap ini dilakukan proses identifikasi sumber model TI di PT Telkom, khususnya dalam pengelolaan SIBORDER. Ada dua jenis sumber TI yang digunakan PT Telkom, yaitu cloud dan insourced. PT Telkom memiliki staff dan layanan TI serta menggunakan cloud untuk menyediakan layanan TI dalam rangka memaksimalkan layanan kepada pelanggan.

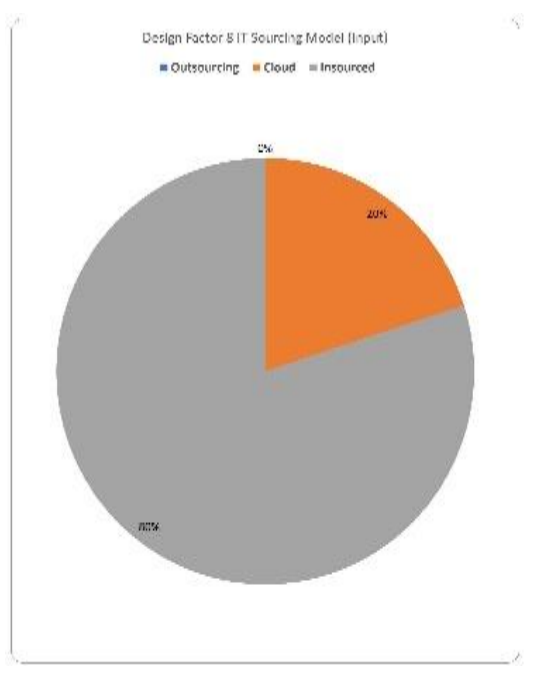

Gambar 12. Faktor Desain 8

\section{9) Faktor Desain 9 IT Implementation Methods}

Tahap ini dilakukan proses indetifikasi metode implementasi TI di PT Telkom dalam pengelolaan SIBORDER. Ada tiga jenis metode implementasi TI yang digunakan dalam pengelolaan, yaitu agile dalam pengembangan perangkat lunaknya, DevOps dimana 
pengembangan perangkat lunak dan operasi TI digabungkan dan traditional dimana merupakan pengembangan yang lebih klasik (waterfall).

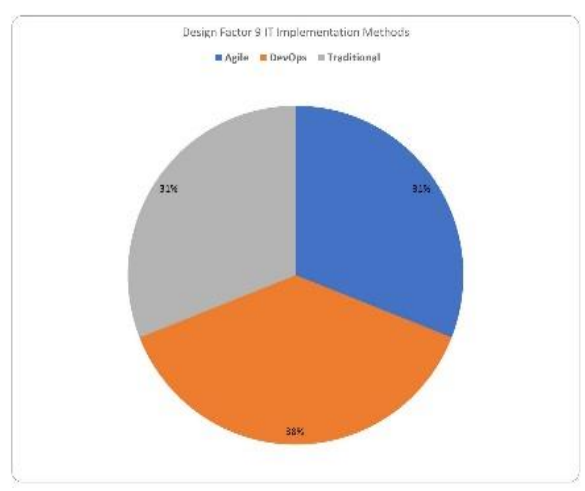

Gambar 13. Faktor Desain 9

10) Faktor Desain 10 Technology Adoption Strategy

Tahap ini dilakukan proses identifikasi strategi PT Telkom dalam mengadopsi TI yang berkaitan dengan SIBORDER. Ada tiga jenis startegi, yaitu first mover, follower dan slow adaptor. PT Telkom cenderung menjadi first mover yang mengadopsi teknologi baru sedini mungkin dan mencoba mendapat keuntungan sebagai penggerak pertama.

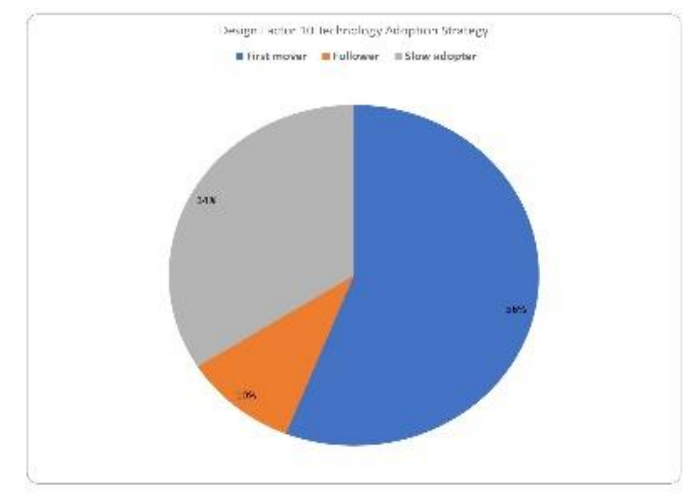

Gambar 14. Faktor Desain 10

11) Faktor Desain 11 Enterprise Size

Merupakan tahap unuk mengidentifikasi ukuran perusahaan dilihat dari jumlah karyawan yang dimiliki. Ada dua jenis ukuran perusahaan dilihat dari jumlah karyawan, yaitu large dan small \& medium. PT Telkom termasuk ke dalam ukuran perusahaan large karena memiliki lebih dari 250 karyawan. 


\section{Tabel 3 Faktor Desain 11}

Jenis Perusahaan

Pilihan Sesuai

Large (Perusahaan dengan lebih dari 250 karyawan tetap)

Small and medium (Perusahaan dengan 50 hingga 250 karyawan tetap )

Dari total 11 faktor desain, selanjutnya dilakukan identifikasi domain dengan pembobotan dan hasilnya dapat dilihat pada Gambar 15. Hasil identifikasi domain yang terpilih sebagai fokus area, yaitu BAI 10 Managed Configuration, DSS 03 Managed Problems, DSS 04 Managed Continuity dan DSS 05 Managed Security Services.

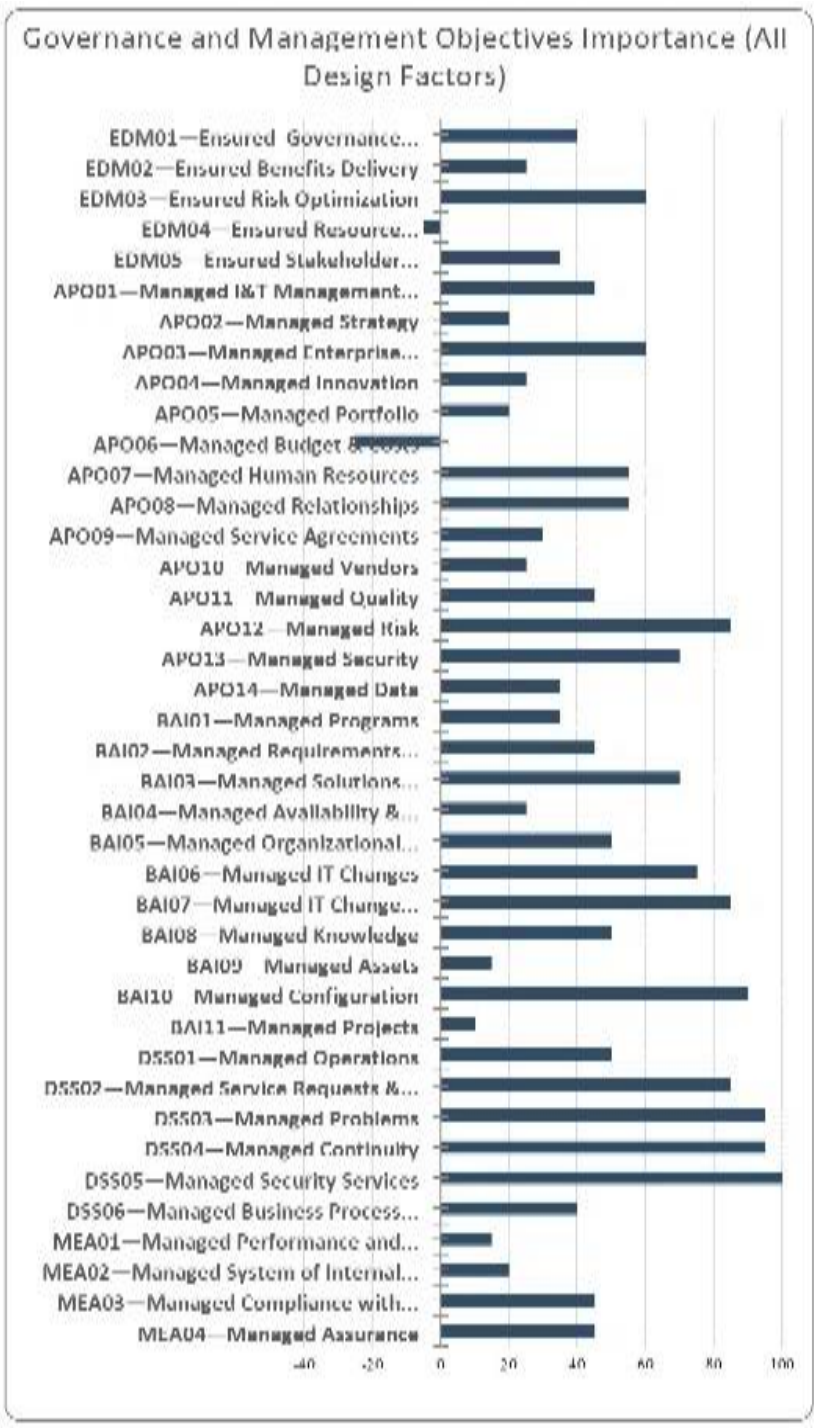

Gambar 15. Grafik hasil pembobotan domain

Selanjutnya, dilakukan kegiatan penyusunan daftar kesesuaian audit berdasarkan domain COBIT 2019 yang telah ditentukan, yaitu domain BAI10, DSS03, DSS04, dan DSS05. Hasil pemetaan RACI Chart, informan kunci untuk pelaksanaan audit tata kelola SIBORDER, 
antara lain Manajer Divisi IT, Staf OSS Platform Operation, Staf IT Support dan Staf IT Security PT Telkom. Informan kunci pelaksanaan audit tata kelola SIBORDER di PT Telkom disajikan pada Tabel IV.

Tabel 4 Hasil Identifikasi Responden Raci Chart

\begin{tabular}{llc}
\hline \multicolumn{1}{c}{ RACI Chart } & \multicolumn{1}{c}{ Struktur Organisasi } & Domain \\
\hline Chief Information Officer & Manajer Divisi IT & BAI10, DSS03, DSS04, DSS05. \\
\hline Head IT Operation & Staf OSS Platform Operation & BAI10, DSS03, DSS04, DSS05. \\
\hline Service Manager & Staf IT Support & BAI10, DSS03, DSS04 \\
\hline Information Security Manager & Staf IT Security Operation & BAI10, DSS03, DSS04, DSS05. \\
\hline
\end{tabular}

Setelah didapatkan informan kunci dari masing-masing domain, langkah selanjutnya adalah pembuatan kuesioner berdasarkan domain COBIT 2019 terpilih, yaitu domain BAI10, DSS03, DSS04, dan DSS05. Kuesioner ini akan digunakan auditor dalam melaksanakan audit tata kelola SIBORDER di PT Telkom. Contoh kuesioner audit tata kelola SIBORDER berdasarkan domain disajikan pada lembar kerja audit pada Gambar 16 dan 17. Informan kunci akan memberikan penilaian kondisi pengelolaan SIBORDER dengan pilihan skor 05 .

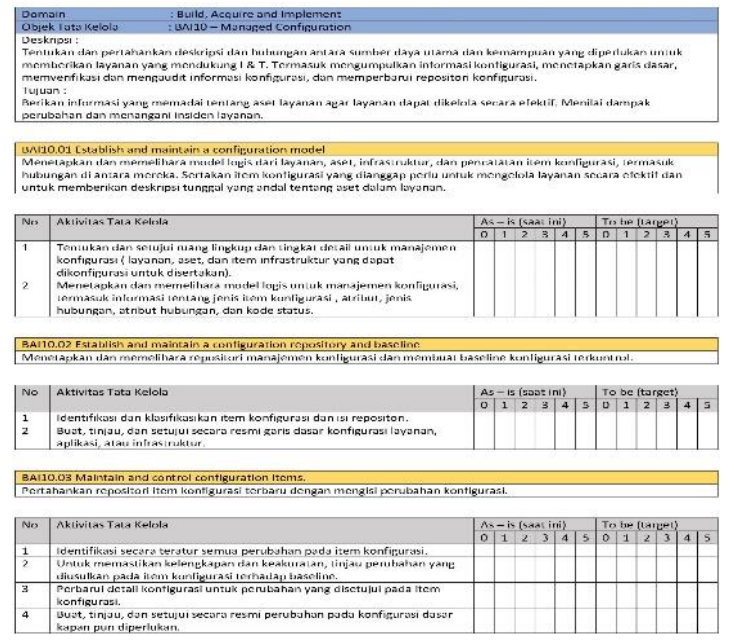

Gambar 16. Lembar kerja audit BAI10

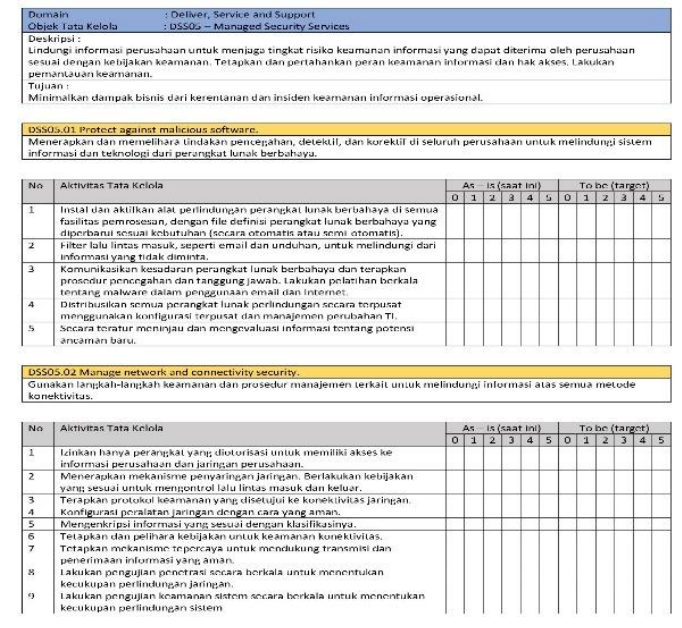

Gambar 17. Lembar kerja audit DSS05

Tahap akhir adalah pembuatan jadwal pelaksanaan kegiatan audit tata kelola SIBORDER di PT Telkom. Tujuannya untuk membantu auditor internal PT Telkom agar kegiatan audit dapat berjalan sesuai dengan perencanaan, sehingga audit dapat berjalan secara efektif dan efisien. Adapun jadwal pelaksanaan audit disajikan pada Gambar 18. 


\begin{tabular}{|c|c|c|c|c|c|c|c|}
\hline \multicolumn{8}{|c|}{$\begin{array}{l}\text { Jadwal Rencana Pelaksanaan Audit Tata Kelola SIBORDER } \\
\text { PT Telekomunikasi Indonesia, TBK. }\end{array}$} \\
\hline \multirow[t]{2}{*}{ No } & \multirow{2}{*}{ Uraian Kegiatan } & \multirow{2}{*}{$\begin{array}{r}\text { Domain yang } \\
\text { akan diaudit }\end{array}$} & \multicolumn{2}{|c|}{ Waktu } & \multirow{2}{*}{ Informan Kunci } & \multirow{2}{*}{$\begin{array}{l}\text { Kode Lembar } \\
\text { Kerja Audit }\end{array}$} & \multirow{2}{*}{ Keterangan } \\
\hline & & & Rencana & Pelaksanaan & & & \\
\hline 1 & $\begin{array}{l}\text { Ruang lingkup audit } \\
\text { SIBORDER }\end{array}$ & & 2 Juli 2021 & & Manajemen & & \\
\hline \multirow[t]{4}{*}{2} & \multirow[t]{4}{*}{ Audit Tata Kelola TI } & BAII0 & 12 Juli 2021 & & \multirow{3}{*}{$\begin{array}{l}\text { - } \text { Manajer Divisi IT, } \\
\text { - Staf OSS Platform Operation, } \\
\text { - Staf IT Support } \\
\text { - Staf IT Security }\end{array}$} & & \\
\hline & & DSS03 & 13 Juli 2021 & & & & \\
\hline & & DSS04 & 14 Juli 2021 & & & & \\
\hline & & DSS05 & 15 Juli 2021 & & $\begin{array}{l}\text { - } \text { Manajer Divisi IT, } \\
\text { - Staf OSS Platform Operation, } \\
\text { - Staf IT Security } \\
\end{array}$ & & \\
\hline 3 & Pemeriksaan Lapangan & & 16-22 Juli 2021 & & Divisi IT & & \\
\hline 4 & $\begin{array}{l}\text { Pelaporan temuan, } \\
\text { hasil dan rekomendasi } \\
\text { audit termasuk dengan } \\
\text { tingkat kematangan } \\
\text { tata kelola SIBORDER }\end{array}$ & & 23 Juli 2021 & & Manajemen & & \\
\hline
\end{tabular}

Gambar 18. Jadwal rencana pelaksanaan audit tata kelola SIBORDER

\section{KESIMPULAN}

PT Telekomunikasi Indonesia Tbk (Telkom) memiliki sistem informasi boost the order (SIBORDER), yaitu sistem informasi yang berfungsi untuk mengawasi proses pemasangan dan upgrade kabel base transceiver station (BTS). SIBORDER perlu dikelola dengan baik, agar fungsi dan proses bisnis usaha dapat berjalan efektif, efisien, dan ekonomis. Pengelolaan TI membutuhkan kerangka kerja, yaitu COBIT 2019 karena telah mengakomodasi tren TI baru, sehingga dapat berfungsi sebagai panduan tak hanya bagi auditor, tetapi juga bagi pengguna dan pihak manajemen untuk menjembatani kesenjangan antara risiko, pengendalian, dan masalah teknis. SIBORDER belum pernah dilakukan audit tata kelola TI. Oleh sebab itu, auditor internal PT Telkom membutuhkan panduan audit tata kelola SIBORDER agar pelaksanaan audit dapat berjalan dengan efektif dan efisien.

Desain panduan audit dimulai dengan proses identifikasi kebutuhan stakeholder, enterprise goals dan pembobotan faktor desain. Hasilnya, kebutuhan stakeholder, yaitu optimalisasi risiko dan sumber daya, sedangkan enterprise goals, yaitu EG01 portofolio produk dan layanan yang kompetitif, EG05 budaya layanan yang berorientasi pada pelanggan, EG06 keberlanjutan dan ketersediaan layanan bisnis dan EG13 inovasi produk dan bisnis. Hasil identifikasi domain yang terpilih sebagai fokus area, yaitu BAI 10 Managed Configuration, DSS 03 Managed Problems, DSS 04 Managed Continuity dan DSS 05 Managed Security Services. Selanjutnya, dilakukan proses penetapan sumber data berdasarkan RACI Chart. Informan kunci dalam pelaksanaan audit, yaitu Manajer Divisi IT, Staff OSS Platform Operation, Staff IT Support dan Staff IT Security Operation. Tahap terakhir, pembuatan 
lembar kerja audit yang berisi daftar pertanyaan untuk penilaian khusus untuk domain terpilih, yaitu BAI 10, DSS 03, DSS 04 dan DSS 05 dan jadwal pelaksanaan audit.

\section{REFERENSI}

Adawiyah, P. A., \& Atrinawati, L. H. (2020). Perancangan Tata Kelola Teknologi Informasi menggunakan Framework COBIT 2019 pada PT. XYZ. Jurnal Teknologi Dan Sistem Informasi (JTSI), 1(1), 1-9.

Anastasia, P. N., \& Atrinawati, L. H. (2020). Perancangan Tata Kelola Teknologi Informasi Menggunakan Framework Cobit 2019 Pada Hotel XYZ. JSI: Jurnal Sistem Informasi (EJournal), 12(2), 1-9. https://doi.org/10.36706/jsi.v12i2.12329

Bayastura, S. F., Krisdina, S., \& Widodo, A. P. (2021). Analisis Dan Perancangan Tata Kelola Teknologi Informasi Menggunakan Framework Cobit 2019 Pada PT. XYZ. JIKO (Jurnal Informatika Dan Komputer), 4(1), 68-75. https://doi.org/10.33387/jiko

Belo, G. I., Wiranti, Y. T., \& Atrinawati, L. H. (2020). Perancangan Tata Kelola Teknologi Informasi Menggunakan Cobit 2019 Pada PT Telekomunikasi Indonesia Regional VI Kalimantan. JUSIKOM PRIMA (Jurnal Sistem Informasi Ilmu Komputer Prima), 4(1), 23-30.

Eko, Y. C., Ali, A. H. N., \& Haryanta, P. (2013). Pembuatan Panduan Audit Teknologi Informasi pada Proses Pengelolaan Lingkungan Fisik Berbasis COBIT 5 di KPPN Surabaya II. Jurnal Teknik Pomits, 2(1), 1-6.

Fariani, R. I. (2014). Pengukuran Tingkat Kemapanan IT Governance PT. Telekomunikasi Indonesia Tbk dilakukan dengan Pendekatan Framework Cobit 4.1. Seminar Nasional Aplikasi Teknologi Informasi (SNATI) Yogyakarta, 21-2014.

Fikri, A. M., Priastika, H. S., Octaraisya, N., Sadriansyah, S., \& Trinawati, L. H. (2020). Rancangan Tata Kelola Teknologi Informasi Menggunakan Framework COBIT 2019 (Studi Kasus: PT XYZ). INFORMATION MANAGEMENT FOR EDUCATORS AND PROFESSIONALS: Journal of Information Management, 5(1), 1-14. https://doi.org/10.51211/imbi.v5i1.1410

Hamsir, M. A., Suwandi, M., \& Juardi, M. S. S. (2017). Analisis Penerapan IT Governance Menggunakan Cobit Framework Dan Sarbanes Oxley Dalam Mendukung Corporate Financial Performance (Studi Kasus Pada PT. Telkom). Jurnal Ilmiah Akuntansi Peradaban, 3(2), 2544.

Lanter, D. (2019). COBIT 2019 Framework Introduction and methodology. In www.icasa.org/COBITuse.

https://community.mis.temple.edu/mis5203sec001sp2019/files/2019/01/COBIT-2019Framework-Introduction-and-Methodology_res_eng_1118.pdf

Meilinda, A. (2016). Analisis Proses Monitoring, Evaluasi dan Penilaian Pengendalian Internal (MEA02 ) Tata Kelola Teknologi Informasi Berdasarkan Kerangka Kerja COBIT 5 Pada PT. 
Telkom Johar Semarang. JOINS (Journal of Information System), 1(1), 11-17. https://doi.org/10.33633/joins.v1i01.1168

Mihai, F. (2010). Auditing IT Governance. Informatica Economica Journal, 14(1), 93-102.

PT Telekomunikasi Indonesia Tbk. (2021). Tentang Telkomgroup. Tekom Indonesia.

Putra, A. W. N., Sunyoto, A., \& Nasiri, A. (2020). Perencanaan Audit Tata Kelola Teknologi Informasi Laboratorium Kalibrasi Menggunakan COBIT 2019 (Studi Kasus: Laboratorium Kalibrasi BSML Regional II). Jurnal Fasilkom, 10(3), 241-247. https://doi.org/10.37859/jf.v10i3.2272

Ramdhany, T., \& Nur'adila, M. D. (2020). Audit Sistem Informasi Pengawasan dan Pemantauan Permintaan Layanan dan Insiden menggunakan COBIT 5 pada PT Telkom Regional Wholesale Service 3 Jawa Barat. Jurnal Nuansa Informatika, 14(1), 10-17.

Riyandi, A., Sudibyo, A., Wijonarko, B., Rinaldi, M., \& Fahlevi, M. F. (2020). Analisa Audit Sistem Informasi Perpustakaan Menggunakan COBIT FrameWork Library Information System Audit Analysis using COBIT FrameWork. Justin, 08(3), 296-302. https://doi.org/10.26418/justin.v8i3.41167

Sari, N. W., Domai, T., \& Panirengu, S. (2014). Penerapan Good Corporate Governance di PT Telkom Malang. Jurnal Administrasi Publik, 2(4), 659-665.

Servanda, M. S., \& Mutiara, A. B. (2018). IT Governance Audit at PT Perusahaan Gas Negara Using Cobit Framework. Jurnal Ilmiah Informatika Komputer, 23(2), 95-106. https://doi.org/10.35760/ik.2018.v23i2.2351

Tambotoh, J. J. C., \& Latuperissa, R. (2014). The Application for Measuring the Maturity Level of Information Technology Governance on Indonesian Government Agencies Using COBIT 4.1 Framework. Intelligent Information Management, 6(1), 12-19.

Waluyab, G., \& Manuputty, A. D. (2016). Evaluasi Kinerja Tata Kelola TI terhadap Penerapan Sistem Informasi Starclick Framework COBIT 5 (Studi Kasus: PT. Telekomunikasi Indonesia, Tbk Semarang). Teknosi, 2(3), 157-166. https://doi.org/10.1038/249668a0 